Volume, 14, número 1, ano, 2018.

\title{
CONTRIBUIÇÕES DA PSICOLOGIA DA EDUCAÇÃO NA FORMAÇÃO DOCENTE (S) EM FRONTEIRA
}

\author{
Maria Luzia da Silva Santana ${ }^{1}$
}

\begin{abstract}
RESUMO: Trata-se de um relato de experiência, cujo objetivo é descrever uma prática pedagógica realizada na disciplina Psicologia, do curso de formação inicial para professores da área de Matemática que é ofertado numa região de fronteira. Procurou-se sensibilizar os futuros educadores quanto a essa problemática no contexto escolar brasileiro e sistematizar uma prática educativa com vistas ao respeito à diversidade, à diferença e voltada à inclusão, sobretudo dos brasiguaios. A partir dessa experiência foi possível instigar o reconhecimento e o empoderamento da diferença, o olhar crítico e respeitoso para com a diversidade que permeia as escolas na região de fronteira, ratificando também a responsabilidade e o papel do professor como mediador na interação e relação positiva entre estudantes brasileiros e brasiguaios.
\end{abstract}

Palavras-Chave: Diversidade. Formação Docente. Fronteira. Psicologia da Educação.

\section{CONTRIBUTIONS OF PSYCHOLOGY OF EDUCATION IN TEACHING TRAINING (S) IN FRONTIER}

ABSTRACT: It is an experience report, whose objective is to describe a pedagogical practice carried out in the discipline Psychology, of the initial training course for teachers in the area of Mathematics that is offered in a border region. The aim was to raise the awareness of future educators about this problem in the Brazilian school context and to systematize an educational practice with a view to respect for diversity, difference and a focus on inclusion, especially the Brazilian. From this experience it was possible to instigate the recognition and empowerment of difference, a critical and respectful look at the diversity that permeates schools in the frontier region, and ratify the responsibility and role of the teacher as a mediator in the interaction and positive relation between Brazilian and Brazilian students.

Key-words: Diversity. Teacher Training. Border. Educational Psychology.

\footnotetext{
1 Doutoranda e Mestra em Psicologia (Universidade Católica de Brasília- UCB); Especialista em Educação e Promoção da Saúde (Universidade de Brasília - UNB) e em Psicologia Social (Universidade Estadual de Santa Cruz-UESC); Psicóloga (Centro de Ciências da Saúde da Universidade Federal do Recôncavo da Bahia- UFRB); Licenciatura Plena em História (Universidade do Estado da Bahia -UNEB) e em Pedagogia (Faculdades Alfredo Nasser - UNIFAN). santanapsi@gmail.com
} 
Volume, 14, número 1, ano, 2018.

\section{Introdução}

As cidades localizadas na região de fronteira são marcadas pela diversidade, pela interação e relação entre diferentes povos. Dentre as cidades brasileiras fronteiriças está Ponta Porã, localizada no Estado de Mato Grosso do Sul, que faz fronteira com a cidade paraguaia de Pedro Juan Caballero. Na fronteira, as pessoas convivem, trocam experiências profissionais, culturais, religiosas e afetivas, que possibilitam novas configurações familiares.

Nesse contexto, é rotineiro encontrar crianças fruto de relacionamentos entre os povos que moram na fronteira, ou que são de origem paraguaia registradas no Brasil, às quais se chamam de "brasiguaios". Entretanto, as relações desenvolvidas na região, que nem sempre são respeitosas, mas marcadas pela confluência de pessoas transitando em proximidade geográfica e humana e na diferença visível na expressão oral, nos gestos, nos ornamentos e na subjetividade. Nesse cotidiano ocorre a construção e o compartilhamento cultural, marcada pelo multiculturalismo que também está presente no contexto de Educação Básica e Superior.

A atuação profissional que perpassa esses dois níveis de educação, requer uma postura docente alicerçada em questionamentos de conhecimentos e de práticas existentes carregadas de ideologias, questões históricas, sociais, políticas, econômicas e culturais e que precisam ser problematizadas à luz das demandas do cotidiano. Assim,

Impõe-se, portanto, fazer avançar a formação na perspectiva de desenvolver, nos estudantes que serão professores, um pensamento social e político mais comprometido com a emancipação da condição humana e mais capaz de empreender rupturas nas concepções ingênuas e nas práticas educativas tradicionais. Posicionamos, pois, a necessidade de contrapor à perspectiva técnica uma perspectiva reflexiva, crítica e emancipatória, que conceba o papel do professor, não como técnico, nem simplesmente um prático, mas o de um intelectual transformador da realidade em que vive (LARROCA, 2007, p.61).

Tendo uma prática pedagógica permeada pela ação-reflexão-ação, entendendo os docentes como "críticos das relações sociais que também se refletem nas salas de aula, tendo como finalidade a formação dos educandos para que se constituam em sujeitos ativos e emancipados" (FEITOSA; BODIÃO, 2015, p.191), foi proposta uma discussão 
REVISTAELETRÔNICA

GRADUAÇÃO/PÓS-GRADUAÇÃO EM EDUCAÇÃO

UFG/REJ

Volume, 14, número 1, ano, 2018.

sobre as ações pedagógicas que sinalizavam marcas de violência contra os estudantes brasiguaios em escolas brasileiras localizadas na região de fronteira.

Perante essa realidade, o problema em discussão aborda os conhecimentos que os estudantes em formação inicial, na Licenciatura em Matemática, têm a respeito das práticas interculturais no contexto de fronteira e suas concepções em relação ao fato de estudantes paraguaios frequentarem escolas brasileiras em Ponta Porã, cidade que faz fronteira seca com Paraguai. A discussão dessa problemática é relevante, uma vez que eles são futuros professores e poderão ter como espaço de atuação profissional escolas com essas características. Assim, esse relato de experiência tem o objetivo de descrever uma prática pedagógica realizada na disciplina Psicologia, do curso de formação inicial para professores da área de Matemática, numa região de fronteira. Os procedimentos metodológicos foram apresentados na seção seguinte.

\section{Caminho Metodológico}

A metodologia adotada se constitui de procedimentos metodológicos realizados nas aulas da disciplina Psicologia, com carga horária de 68 horas, especificamente em sua terceira unidade realizada em 22 horas-aulas, nas quais foram discutidos temas relativos à aprendizagem e ao desenvolvimento dos estudantes brasiguaios no contexto escolar de fronteira, bem como as práticas pedagógicas na área de Matemática. Essa disciplina foi desenvolvida durante o primeiro semestre letivo do ano de 2016, com dois encontros semanais, de duas horas aulas cada um, com uma turma do $3^{\circ}$ período do curso de Licenciatura em Matemática, ofertado pela Universidade Federal de Mato Grosso do Sul, no Campus de Ponta Porã.

$\mathrm{Na}$ referida disciplina estavam matriculados 10 estudantes, sendo que um nunca frequentou a disciplina e um desistiu, devido à incompatibilidade das atividades profissionais com o horário das aulas que aconteceram no período noturno. Dos 10 estudantes, 5 eram do sexo feminino e 5 do sexo masculino. Na disciplina Psicologia, além de trabalhar as teorias clássicas (Behaviorismo, Epistemologia Genética, Psicogênese da Pessoa Completa, Perspectiva Histórico Cultural, Aprendizagem Significativa e o Humanismo) sobre aprendizagem e desenvolvimento humano, como estratégia de ensino-aprendizagem, foi incluída uma discussão de artigos e dissertações 


\section{HIVERTIIS REVISTAELETRONICA

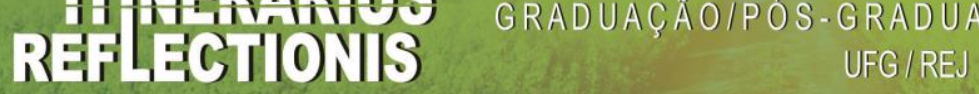

Volume, 14, número 1, ano, 2018.

publicadas sobre a educação dos estudantes brasiguaios em escolas brasileiras de fronteiras entre Brasil/Paraguai e a sistematização de uma prática pedagógica com vistas às demandas desses contextos educativos.

As pesquisas selecionadas para discussão com a turma foram as realizadas em Ponta Porã, no estado de Mato Grosso do Sul, porque elas sinalizam a necessidade de (re)visitar as práticas pedagógicas desenvolvidas por professores dessa cidade, por serem marcadas pelo preconceito, principalmente nas escolas próximas à faixa de fronteira que atendem estudantes brasiguaios. Assim, procurou sensibilizar os futuros educadores quanto a essa problemática no contexto escolar brasileiro e sistematizar uma prática educativa com vistas à diversidade, à diferença e voltada à inclusão, sobretudo dos estudantes brasiguaios. Os depoimentos de três estudantes (E1, E2 e E3), assim como os resultados as propostas de trabalhos apresentados por eles foram problematizadas nesse relato de experiência.

\section{Aspectos Históricos da Educação Inclusiva}

Discorrer sobre a educação inclusiva na / para a diversidade, demanda situar o seu percurso histórico, pontuando os avanços e os dilemas existentes, assim como demarcar as ideias dos teóricos sobre a constituição do ser humano. Na primeira metade do século XX a deficiência era vista apenas pelo enfoque das causas orgânicas e pelo prisma do inatismo (MARCHESI, 2010). O viés inatista contribuiu com o processo de biologização e normatização da subjetividade e singularidade da pessoa com deficiência, pautado no princípio de que a "deficiência é percebida a partir do viés quantitativo de ausência, como um defeito, uma falha e um empecilho para o desenvolvimento linear esperado" (SANTANA et al. 2016, p.51).

A partir dos anos de 1960, os movimentos sociais, a experiência de profissionais e os avanços na área do desenvolvimento humano possibilitaram mudanças nos conceitos que se tinha sobre a deficiência. Observa-se uma maior

[...] aceitação de uma nova maneira de entender a deficiência a partir de uma perspectiva educacional. São dois os fenômenos mais relevantes dessa nova aproximação: no plano conceitual, um novo enfoque baseado na análise das necessidades educativas dos alunos; no plano da prática educativa, o desenvolvimento da integração educativa, que impulsiona, ao mesmo tempo, mudanças na concepção do 
REVISTAELETRÔNICA

GRADUAÇÃO/PÓS-GRADUAÇÃO EM EDUCAÇÃO

UFG/REJ

Volume, 14, número 1, ano, 2018.

currículo, na organização das escolas, na formação de professores e no processo de ensino na sala de aula (MARCHESI, 2010, p.19).

Essa visão abriu caminho para descentralizar o olhar na falta, na deficiência e possibilitou investimentos nas potencialidades de desenvolvimento das pessoas com deficiência. Destarte, “a ênfase se desloca, pois, do 'aluno com defeito' para situar-se na resposta educativa da escola, sem que isso represente a negação da problemática vivida pelo educando" (CARVALHO, 2010, p.42). As mudanças também perpassaram o uso da terminologia utilizada, que passou a ser pessoa com "necessidades educativas especiais" a partir da década de 1960. No entanto, essas mudanças foram insuficientes para transformar a organização na educação especial (MARCHESI, 2010).

Em finais da década de 1970, o informe de Warnock sobre as condições da educação especial inglesa, reconheceu que o agrupamento das dificuldades das crianças em categorias fixas não é benéfico (MARCHESI, 2010). Nesse contexto histórico e social, tal ideia era considerada revolucionária por colocar em xeque o trabalho desenvolvido com estudantes deficientes. O uso da terminologia e as ideias sucintas sobre as necessidades educativas especiais geraram críticas - tanto favoráveis quanto contrárias ao seu uso, mas é inegável que os pressupostos de Warnock "intensificaram a discussão acerca da educação especial, bem como das propostas de integração" (CARVALHO, 2010, p. 45).

A Declaração de Salamanca (1994) também é outro marco histórico importante no percurso da educação inclusiva na e para a diversidade.

O princípio que orienta essa estrutura (de ação em educação especial) é o de que escolas deveriam acomodar todas as crianças, independentemente de suas condições físicas, intelectuais, sociais, emocionais, linguísticas ou outras. Aquelas deveriam incluir crianças deficientes ou superdotadas, crianças de rua e trabalhadoras, crianças de origem remota ou de população nômade, crianças pertencentes a minorias linguísticas, étnicas ou culturais e crianças de outros grupos inferiorizados ou marginalizados [...] (DECLARAÇÃO DE SALAMANCA, 1996, p. 3).

É interessante pontuar que essas ideias-chave têm seus primórdios no início dos anos de 1970 sendo "retomadas sob o paradigma da escola de boa qualidade para todos, uma escola inclusiva" (CARVALHO, 2010, p. 45). Ratificando esse pensamento, "o movimento no sentido das escolas inclusivas procede, em grande medida, do campo da educação especial que se propôs a atingir uma mudança profunda na educação, que seja capaz de integrar todos os alunos" (MARCHESI, 2010, p. 27). 


\section{HIVERARIIS REVISTAELETRONICA

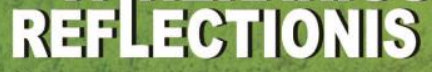

Volume, 14, número 1, ano, 2018.

Quanto à educação e inclusão em Ponta Porã os dados (Tabela 1) demonstram que já existe a inserção de estudantes em escolas regulares. Em Ponta Porã os estudantes de educação especial incluem: Educação Infantil em que foram registradas 8 matrículas; 295 estudantes constam das turmas dos Anos Iniciais do Ensino Fundamental; 117 nos Anos Finais; 31 no ensino Médio; e 20 na Educação de Jovens e Adultos (INEP, 2015). No entanto, ao considerar os pressupostos da Declaração de Salamanca (1996); que sustenta a ideia de educação para todos, independentemente das características físicas, intelectuais, sociais, emocionais, linguísticas, étnicas ou culturais dos estudantes; é possível sugerir que as escolas apresentadas em pesquisas (DALINGHAUS, 2013; MELO et al. 2016; NUNES, 2011; PEREIRA, 2009) realizadas na região fronteiriça

têm o grande desafio de incluir de fato os brasiguaios, aspecto que envolve a ressignificação das relações e práticas constituídas nos contextos educativos. Assim, é possível apontar que os estudantes de (ou matriculados em) escolas brasileiras, que têm origem identitária diferente, incluindo os paraguaios e os brasiguaios, devem ser alvo de políticas públicas de inclusão para o desenvolvimento positivo dessa diversidade. 


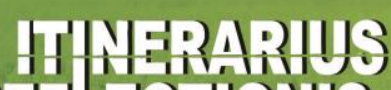

REVISTAELETRÔNICA

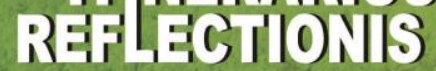

GRADUAÇÃO/PÓS-GRADUAÇÃO EM EDUCAÇ,̃̃O

UFG/REJ

Volume, 14, número 1, ano, 2018.

Tabela 1 - Número de matrículas na educação especial em Ponta Porã -MS

\begin{tabular}{|c|c|c|c|c|c|c|c|c|c|c|c|c|}
\hline \multirow{5}{*}{$\begin{array}{c}\text { UNIDADES DA FEDERAÇÃO } \\
\text { MUNICÍPIOS } \\
\text { DEPENDÊNCIA ADMINISTRATIVA }\end{array}$} & \multicolumn{12}{|c|}{ MATRÍCULA INICIAL } \\
\hline & \multicolumn{10}{|c|}{ EDUCAÇÃO ESPECIAL (ALUNOS DE ESCOLAS ESPECIAIS, CLASSES ESPECIAIS E INCLUÍDOS) } & \multirow{2}{*}{\multicolumn{2}{|c|}{$\begin{array}{c}\text { EJA } \\
\text { EJA Presencial }\end{array}$}} \\
\hline & \multicolumn{4}{|c|}{ Educação Infantil } & \multicolumn{4}{|c|}{ Ensino Fundamental } & \multirow{2}{*}{\multicolumn{2}{|c|}{ Médio }} & & \\
\hline & \multicolumn{2}{|c|}{ Creche } & \multicolumn{2}{|c|}{ Pré- escola } & \multicolumn{2}{|c|}{ Anos Iniciais } & \multicolumn{2}{|c|}{ Anos Finais } & & & \multirow{3}{*}{ Fundamental } & \multirow{3}{*}{ Médio } \\
\hline & Parcial & Integral & Parcial & Integral & Parcial & Integral & Parcial & Integral & Parcial & Integral & & \\
\hline \multicolumn{11}{|l|}{ PONTA PORA } & & \\
\hline Estadual Urbana & 0 & 0 & 0 & 0 & 76 & 0 & 59 & 0 & 21 & 0 & 5 & 0 \\
\hline Estadual Rural & 0 & 0 & 0 & 0 & 49 & 5 & 39 & 0 & 10 & 0 & 3 & 1 \\
\hline Municipal Urbana & 1 & 0 & 7 & 0 & 142 & 16 & 15 & 0 & 0 & 0 & 10 & 0 \\
\hline Municipal Rural & 0 & 0 & 0 & 0 & 1 & 6 & 1 & 3 & 0 & 0 & 1 & 0 \\
\hline Estadual e Municipal & 1 & 0 & 7 & 0 & 268 & 27 & 114 & 3 & 31 & 0 & 19 & 1 \\
\hline \multicolumn{13}{|c|}{ ENSINO REGULAR } \\
\hline Estadual Urbana & 0 & & 0 & 0 & 1.627 & 57 & 3.522 & 12 & 2.750 & 0 & 319 & 573 \\
\hline Estadual Rural & 0 & 0 & 0 & 0 & 1.054 & 40 & 1.430 & 5 & 653 & 1 & 102 & 49 \\
\hline Municipal Urbana & 298 & 627 & 1.529 & 0 & 4.673 & 669 & 1.332 & 5 & 0 & 0 & 296 & 0 \\
\hline Municipal Rural & 0 & 0 & 194 & 13 & 312 & 258 & 84 & 167 & 0 & 0 & 64 & 0 \\
\hline Estadual e Municipal & 298 & 627 & 1.723 & 13 & 7.666 & 1.024 & 6.368 & 189 & 3.403 & 1 & 781 & 622 \\
\hline
\end{tabular}

Fonte: INEP, 2015 


\section{Volume, 14, n.1, Ano 2017.}

$\mathrm{Na}$ historicização do percurso da educação inclusiva, é possível sugerir que as discussões de Vigotski sobre a defectologia, realizadas entre as décadas de 20 e 30 do século XX, também sinalizam e potencializam a inclusão na/para a diversidade, ao postular que:

[...] a história do desenvolvimento cultural da criança permite propor a seguinte tese: o desenvolvimento cultural é a principal esfera em que é possível compensar a deficiência. Onde não é possível avançar no desenvolvimento orgânico, abre-se um caminho sem limites para o desenvolvimento cultural (VIGOTSKI, 2011, p.869).

Numa vertente social e cultural sobre a constituição do psiquismo humano e da deficiência, Vigotski (2011) introduziu na área da educação a compreensão dialética do desenvolvimento da criança, salientando que há implicações da aprendizagem escolar na transformação das funções naturais e na reconstrução do curso do pensamento natural da criança. Assim,

[...] o educador começa a compreender que, ao entrar na cultura, a criança não apenas toma algo dela, adquire algo, incute em si algo de fora, mas também a própria cultura reelabora todo o comportamento natural da criança e refaz de modo novo todo o curso do desenvolvimento. A distinção de dois planos de desenvolvimento no comportamento (o natural e o cultural) torna-se o ponto de partida para uma nova teoria da educação (VIGOTSKI, 2011, p.864-5).

A perspectiva de Vigotski rompe com a ideia da constituição humana puramente biológica, imutável e universal, sendo que os instrumentos e signos passam a ser entendidos como mediadores das relações humanas e sociais. Assim, o processo de constituição da pessoa tem íntima relação com a mediação e internalização do mundo objetivo, da sua realidade que envolve fatos, acontecimentos, funções e significados que são elementos marcados pela cultura.

\section{Multiculturalismo, Diversidade e Inclusão}

A constituição do psiquismo humano tem relação com os processos culturais que incluem uma série de alterações. A partir do prisma vigotskiano, o desenvolvimento mental é marcado pela interiorização das funções psicológicas superiores, que não é simplesmente a transferência de uma atividade externa para um plano interno, mas envolve todo o processo no qual esse interno é constituído. Ou seja, a constituição da pessoa envolve mudanças na condição da atividade externa para interna e transformação do processo interpessoal para intrapessoal, que é resultado de eventos ocorridos ao longo do desenvolvimento da pessoa (VIGOTSKI, 2007). O que é interiorizado é fruto 


\section{Volume, 14, n.1, Ano 2017.}

da constituição histórica, cultural e social, sendo a linguagem o principal mediador na formação e no desenvolvimento das funções psicológicas superiores. Ela constitui um sistema simbólico, elaborado no curso da história social do homem (VIGOTSKI, 2009). A linguagem materializa e constitui as significações desenvolvidas no processo sóciohistórico-cultural, possibilitando expressar as formas de sentir, pensar e agir no mundo e a tomada de consciência. Tal pressuposto possibilita afirmar que as discriminações existentes - nas quais alguns são valorizados em detrimento da inferiorização de outros , a exemplo do olhar ainda existente sobre a deficiência e dos categorizados como "diferentes" - são constituídas nas relações interpessoais, sendo a instituição educacional também palco dessas interações que poderão potencializar a garantia de direitos humanos, o empoderamento da diversidade e a convivência na e da diferença ou, por outro lado, reforçar o preconceito e a discriminação.

As diferenças incluem desde as questões físicas, culturais, étnico-raciais, religiosas, de gênero, de nacionalidade, a diversidade sexual e tantas outras existentes, caracterizadoras da existência humana e que se fazem presentes no contexto educativo. Candau (2012) na análise dos diversos elementos que configuram a escola e das fundamentais questões colocadas para o desenvolvimento do papel docente pontua que:

[...] em inúmeras pesquisas desenvolvidas, a constatação do caráter homogeneizador e monocultural das culturas escolares é recorrente. A escola continua predominantemente privilegiando um referente cultural único, reconhecendo conhecimentos provenientes de uma única tradição epistemológica e sociocultural como legítimos e dignos de integrar o currículo escolar e estratégias didático-metodológicas homogêneas (CANDAU, 2012, p. 187).

Os pressupostos na vertente do multiculturalismo intercultural propõem uma educação possibilitadora de igualdade para a vivência e convivência democrática da diferença. Assim, a referida autora "propõe um multiculturalismo aberto e interativo, que acentua a interculturalidade por considerá-la mais adequada para a construção de sociedades democráticas, pluralistas e inclusivas, que articulem políticas de igualdade com políticas de identidade" (CANDAU, 2008, p.22).

Os processos de inclusão na educação precisam pautar-se "na construção de uma educação escolar realmente democrática, que articule igualdade e reconhecimento das diferenças. Valorize os diversos sujeitos, saberes e práticas ancorados em diversas tradições culturais" [...] (CANDAU, 2012, p. 190-1). Essa perspectiva de contribuir com a formação de professores que possam atuar de maneira crítica, respeitando e 


\section{Volume, 14, n.1, Ano 2017.}

empoderando a diversidade e na garantia dos direitos humanos norteou as discussões e atividades da disciplina Psicologia.

A proposta nessa disciplina do curso de formação de professores pretendeu ir de encontro às práticas pedagógicas marcadas pela violência contra os estudantes brasiguaios no contexto escolar brasileiro e que foram evidenciadas em diversos estudos (DALINGHAUS, 2013; JOSGRILBERT; BOUFLEUR, 2012; MELO et al. 2016; NUNES, 2011; PEREIRA, 2009). Assim, buscou-se demonstrar a importância das contribuições da educação intercultural com vistas na reinvenção da escola "como um lócus privilegiado de formação de novas identidades e mentalidades capazes de construir respostas, sempre com caráter provisório, para as grandes questões que enfrentamos hoje, tanto no plano local, quanto nacional e internacional" (CANDAU, 2012, p. 190-1).

Há práticas preconceituosas e discriminatórias em relação aos brasiguaios, a exemplo de zombarias e chacotas, como os apelidos que recebem de "chipa" (nome de um salgadinho parecido com o tradicional pão de queijo brasileiro) e "chipeiro" (o vendedor da chipa) (PEREIRA, 2009). Um dos elementos constituintes do estudante brasiguaios é a sua língua materna, deixada à margem no contexto escolar brasileiro.

Os estudantes oriundos de Pedro Juan Caballero (Paraguai), ao serem matriculados na rede de ensino público brasileiro, em Ponta Porã, encontram dificuldades de adaptação, pois os envolvidos na prática educacional não se mostram preparados para atender às suas demandas. Eles não são empoderados e valorizados como estudantes bilíngues (guarani/português, espanhol/guarani, guarani/espanhol) ou trilíngues. Para melhores condições de aprendizagem desses estudantes, é preciso levar em consideração essa singularidade e direcionar a prática pedagógica ao viés do multilinguismo e da interculturalidade, presentes nessa região fronteiriça.

\section{Formação de Professores na Região de Fronteira}

As dificuldades, enfrentadas pelos brasiguaios em escolas brasileiras, são desconhecidas por parte de estudantes que estão nos semestres inicias dos cursos de Licenciatura em Matemática na região de fronteira. Quando a problemática foi suscitada pela primeira vez na aula da disciplina Psicologia, um dos estudantes denominado aqui de E1, 


\section{Volume, 14, n.1, Ano 2017.}

expressou que os estudantes brasiguaios que "estão em escolas brasileiras, devem se adaptar a ela" (E1).

Essa frase parece encontrar eco na pesquisa desenvolvida por Nunes (2011, p. 211) que “expressa com clareza a concepção de grande parte dos demais professores de Geografia sobre a presença do aluno de origem paraguaia nas escolas de Ponta Porã”. No entanto, o referido estudante (E1) não tinha tido contato com essa pesquisa; ao contrário, desconhecia a existência de estudos que problematizavam essa realidade educacional da fronteira, chegando mesmo a afirmar que "essas pesquisas que a senhora está falando devem ser sobre outros locais, professora" (E1).

Por outro lado, a marca do preconceito e desrespeito aos direitos humanos na fronteira não é despercebida por outros estudantes, a exemplo da colocação da estudante (E2) “acontece o preconceito sim! Os alunos brasiguaios são proibidos de falar em espanhol ou guarani”, o que corrobora os estudos de Dalinghaus (2013); Melo et al. (2016); Nunes (2011) e Pereira (2009) sobre a educação em Ponta Porã e que problematizam o tema em tela.

A partir desses posicionamentos inicias dos estudantes E1 e E2, verificou-se a necessidade de aprofundamento da discussão sobre "as ações pedagógicas e os estudantes brasiguaios no contexto brasileiro". Assim, além dos textos que tratavam dos aspectos epistemológicos sobre Psicologia da Educação, também foram trazidos para o centro do debate, na disciplina de Psicologia, pesquisas que gravitaram em torno dessa temática. Ao propor a problematização sobre a prática educativa e o cotidiano escolar de fronteira, almejava-se que "além de propiciar uma interpretação crítica da experiência vivenciada, pode conduzir o educador a um processo de criação, que transcende à mera aplicação de esquemas de intervenções resultantes de saberes aplicados (FEITOSA; BODIÃO, 2015, p.193).

Buscou-se, a partir da compreensão dessa realidade, a sistematização de uma ação docente voltada para a prática pedagógica permeada pela diversidade e diferença, principalmente destacando a necessidade de contribuir para o desenvolvimento do multiculturalismo intercultural na faixa de fronteira. Assim, as discussões desenvolvidas não perderam de vista, na formação do professor, a compreensão de homem como sujeito histórico e cultural que se constitui e se torna humanizado na relação com o outro. 
Volume, 14, n.1, Ano 2017.

Deste modo, na terceira unidade da disciplina Psicologia, focalizou-se o desenvolvimento do estudante brasiguaio que, independentemente de sua origem, deve ser visto como um ser humano na acepção humanista de Rogers, que se desenvolve na relação como o outro, conforme a perspectiva histórico-cultural de Vigotski, com possibilidade de ter uma aprendizagem significativa pelo viés de Ausubel. As ideias desses pesquisadores foram discutidas com o intuito de contribuir para a formação de uma postura ética e humana do professor, além de instrumentalizá-lo para a elaboração e adoção de uma metodologia de ensino potencializadora do respeito à diversidade e ao multiculturalismo.

Em relação a importância dos aspectos teóricos Feitosa e Bodião (2015) pontuam que mesmo reconhecendo que a construção do conhecimento vem da prática, não há como situá-lo somente nela. É necessária também uma sólida base teórica, que possibilita subsidiar a resolução de problemas emergentes no cotidiano escolar. Assim,

[...] a docência deve ser um movimento operacionalizado simultaneamente pela ação-reflexão, ou seja, uma ação humana que traga, no seu interior, a inseparabilidade entre teoria e prática e essa polaridade complementar deve ser exercitada desde as dinâmicas formativas dos futuros professores (FEITOSA; BODIÃO, 2015, p.193).

Ao discutir sobre os percursos e dilemas de algumas escolas de Ponta Porã quanto a educação na/para a diversidade, possibilita-se aos estudantes do curso de formação para o magistério dessa região uma reflexão sobre a prática profissional para

[...] enfrentar as questões colocadas por esta mutação cultural, o que supõe não somente promover a análise das diferentes linguagens e produtos culturais, como também favorecer experiências de produção cultural e de ampliação do horizonte cultural dos alunos e alunas, aproveitando os recursos disponíveis na comunidade escolar e na sociedade (CANDAU, 2008, p.35).

O fazer educativo é um dos principais recursos que poderão possibilitar o respeito à diferença no ambiente escolar. Diante disso, como trabalho final da disciplina Psicologia, foi proposto que os estudantes apresentassem sugestões de metodologias para aulas de Matemática na região de fronteira.

Essa atividade contemplou uma revisão de literatura para situar a educação Básica no contexto de Ponta Porã, discutindo e articulando as contribuições de Vigotski, Rogers e Ausubel no que tange à constituição do ser humano e o processo de ensinoaprendizagem; também contemplou uma proposta de aula com temática livre, mas que não perdesse de vista a realidade das escolas, que são perpassadas pela diversidade e 


\section{Volume, 14, n.1, Ano 2017.}

diferença. Cada estudante socializou com a turma o seu trabalho final. Os temas e os objetivos das propostas de aulas apresentadas pelos estudantes E1, E2 e E3 foram sumariadas e são apresentadas a seguir.

E1 apresentou como temática "O professor de matemática na região de fronteira Ponta Porã - BR e Pedro Juan Caballero-PY: aula sobre equações do $1^{o}$ grau com uma incógnita". Os objetivos propostos foram: apresentar o conteúdo, de forma dinâmica e ilustrativa, fazendo paralelo com uma balança, além de utilizar, dentro dos conceitos, a construção do mapa conceitual em dois idiomas, Português e Espanhol. A metodologia utilizada, como se pode perceber, instiga o respeito à diversidade, principalmente, quanto ao idioma, além de propiciar a integração, já que os que não falam espanhol dependerão dos falantes desse idioma para a realização da atividade.

Os problemas poderiam ser apresentados em espanhol, para construir uma relação entre os alunos que falam outro idioma com os que falam apenas, o português. Eles irão perguntar aos seus colegas o significado de algumas palavras que possam vir a não entender. Assim, de certa forma, será incentivada uma relação próxima com cada aluno no ambiente escolar (E 1).

Ao apresentar atividades que explorem a realidade local, o aluno sente-se mais motivado para resolver algo que ele vivencia. Outro fator importante é o diálogo dos alunos bilíngues com alunos que falam apenas o português. Os "brasiguaios" não vão mais se sentir inferiorizados e, se algumas questões forem em espanhol, será uma maneira de valorizar o seu idioma (E 1).

E2 elegeu como temática para ser desenvolvida nas aulas, "O professor de Matemática na região de fronteira Ponta Porã-BR e Pedro Juan Caballero-PY: aula sobre gráficos". Os objetivos propostos foram: estimular os alunos para a compreensão dos conceitos básicos de gráficos; demonstrar a utilização de gráficos na realidade da fronteira; explicar os conceitos de gráficos. Os procedimentos metodológicos possibilitariam a discussão e reflexão sobre a diversidade cultural, ao serem utilizadas as moedas que circulam na fronteira e também na exploração da taxa de natalidade do município de Ponta Porã.

Uma proposta a ser utilizada em um plano de aula para escolas com essa mistura de culturas, é desenvolver a aula expondo situações matemáticas cotidianas dos alunos dos dois lados da fronteira, como o real e o guarani, o preço do material escolar nos dois países, etc. [...] Será trabalhado o tema gráficos, mas antes de introduzir o assunto, serão levantadas situações reais e demonstrações de gráficos com informações de ambos os países. Depois, quando os alunos já estiverem mais familiarizados com o assunto, será construído um gráfico em conjunto com eles, demonstrando o crescimento populacional de Ponta Porã, e destacando que muitos brasiguaios nascem no Paraguai, mas são registrados em Ponta Porã, aumentando a população e trazendo um crescimento positivo para a cidade (E2).

A valorização da língua materna do estudante brasiguaio, a partir da acepção de Vigotski (2007, 2009) é importante, por ser um dos instrumentos que contribui para 


\section{Volume, 14, n.1, Ano 2017.}

formação do psiquismo humano, além dela tornar possível lidar com objetos ausentes; fazer abstrações, análises e generalização dos elementos constituintes do mundo físico, além de possibilitar a comunicação. Assim,

[...] a capacitação especificamente humana para a linguagem habilita as crianças a providenciar instrumentos auxiliares na solução de tarefas difíceis, a superar a ação impulsiva, a planejar uma solução para um problema antes de sua execução e a controlar seu próprio comportamento. Signos e palavras constituem para as crianças, primeiro e acima de tudo, um meio de contato social com outras pessoas. As funções cognitivas e comunicativas da linguagem tornam-se, então, a base de uma forma nova e superior de atividade nas crianças, distinguindo-as dos animais (VIGOTSKI, 2007, p.17-8).

As ferramentas de comunicação e expressão possibilitam a construção do ser humano. Se, de alguma forma, o estudante é impedido de se expressar na sua língua materna, poderá estar sendo privado de um dos instrumentos importantes para o seu processo de aprendizagem e desenvolvimento.

Os estudantes oriundos do Paraguai apresentam dificuldades na aprendizagem da língua portuguesa em escolas brasileiras, por ser um idioma diferente que, mesmo tendo palavras iguais ou semelhantes ao espanhol podem ter significados completamente diferentes. Assim, compreender o professor em sala de aula, interagir com os outros estudantes e estabelecer relações de amizades, pode ser uma tarefa difícil para os brasiguaios. Nesse contexto "o/a educador/a tem um papel de mediador na construção das relações interculturais positivas, o que não elimina a existência de conflitos. $O$ desafio está em promover situações sem que seja possível o reconhecimento entre os diferentes" [...] (CANDAU, 2008, p.30).

E3 construiu a proposta "O professor de Matemática na região de fronteira Ponta Porã-BR e Pedro Juan Caballero - PY: aula sobre múltiplos e MMC, a partir das eleições". Os objetivos propostos foram: entender o conceito de multiplicidade e MMC e resolver problemas tendo como base a região da fronteira. Conforme E3, na região de fronteira um professor poderá trabalhar de maneira diversificada utilizando, por exemplo, o câmbio entre o real, o guarani e o dólar. Metodologicamente os procedimentos citados foram;

[...] tendo em vista as eleições presidenciais/municipais que ocorrem a cada 4 anos no Brasil e a cada 5 anos no Paraguai, pode-se trabalhar com múltiplos e MMC: a cada quantos anos Brasil (Ponta Porã) e Paraguai (Pedro Juan Caballero) terão eleições juntos? Estas eleições ocorrem no mesmo período? Qual foi o último ano que ocorreram eleições juntamente nos dois países? São questões a serem trabalhadas acerca de um conteúdo matemático e que pode, de certa forma, integrar os alunos e trabalhar algo relativo ao cotidiano [...] É importante trabalhar com isto, pois os alunos paraguaios se sentirão incluídos, e além disso, poderão debater em sala não só os conceitos de múltiplos, bem como, o modo que as coisas 


\section{Volume, 14, n.1, Ano 2017.}

funcionam, histórias que vivenciaram, alguns costumes, parte de sua cultura que é de certa forma renegada quando chegam às escolas brasileiras (E3).

Os procedimentos metodológicos propostos por E1, E2 e E3 poderão ser adequados para serem trabalhados em diferentes disciplinas. Pensando nisso, é aconselhável que os educadores na região de fronteira usem metodologias de ensino, com foco em ações multi ou interdisciplinares, para favorecer o respeito aos estudantes "brasiguaios" no contexto escolar brasileiro, levando em consideração a valorização de sua língua materna, mediando a comunicação nesses espaços em duas ou três línguas. Tal postura vai ao encontro de práticas transformadoras que,

[...] valorizam-se os conteúdos escolares, tratando-os a partir das experiências sociais vividas no cotidiano dos alunos, fortalecendo-se o papel de mediação que a escola deve exercer entre as vivências individuais e suas articulações com as grandes questões sociais e políticas, seja da sua cidade, do seu país ou do próprio planeta Terra (FEITOSA; BODIÃO, 2015, p.196).

A prática pedagógica na perspectiva da transformação social e de inclusão da diversidade na região de fronteira deverá ser rotina nas escolas e dos professores de todas as matérias. Sugere-se que, em cada conteúdo trabalhado em sala de aula, haja um eixo norteador que contemple a diversidade identitária e cultural da região, que poderá envolver atividades de pesquisas que considerem além dos conteúdos científicos cobrados pelos órgãos oficiais de educação.

As atividades que potencializem o respeito à diversidade e o fortalecimento de vínculos entre os estudantes brasileiros e brasiguaios deverão ser elementos constituintes de práticas educativas nas escolas de Ponta Porã. Através de ações pedagógicas com esse caráter, o espaço educativo poderá ser mais inclusivo, com interações e relações favorecedoras do respeito e garantia dos direitos humanos e da cidadania na escola.

Os métodos de ensino adotados pelos docentes devem possibilitar uma prática pedagógica inclusiva que ultrapasse as fronteiras estabelecidas contra a diferença. Tal aspecto requer a adoção próxima ou - na perspectiva da educação intercultural democrática que considera a igualdade, o reconhecimento da diferença e que "valorize os diversos sujeitos, saberes e práticas ancorados em diversas tradições culturais e se comprometa com um horizonte de emancipação social” [...] (CANDAU, 2012, p. 191).

\section{Considerações Finais}




\section{Volume, 14, n.1, Ano 2017.}

É possível que os estudantes em formação, se depararão com as demandas evidenciadas nas pesquisas sobre a educação na região de fronteira ou com problemáticas próximas; por isso, buscou-se contribuir com "o desenvolvimento da capacidade reflexiva é uma condição necessária para que o profissional construa suas próprias teorias acerca da ação que pratica, do campo em que atua e dos fins que persegue com a sua atividade" (LARROCA, 2007, p.61).

A experiência com estudantes em formação para o magistério possibilitou instigar o reconhecimento e o empoderamento da diferença, o olhar crítico e respeitoso para com a diversidade que permeia as escolas na região de fronteira. Nas palavras de E1 as ações pedagógicas da disciplina Psicologia "mudaram a ideia inicial que eu tinha em relação à educação na fronteira [...] ajudaram a desconstruir um preconceito que eu tinha dos paraguaios e brasiguaios porque não estudavam no país deles".

Ajudaram também a ratificar a responsabilidade e o papel do professor como mediador da interação e relação entre estudantes brasileiros e brasiguaios e a contribuição para o seu desenvolvimento positivo. "Cada vez que impedimos a criança de ser livre, estamos comentando uma violência contra o desenvolvimento dela" (E1), assim "o aluno não pode ser privado de expressar na sua língua materna" (E2).

A disciplina de Psicologia na formação de professores de Matemática em e sem fronteira pressupõe considerar como diretriz norteadora a tríade: o estudante que o professor tem diante de si; a realidade educacional, escolar e social; e as diferentes contribuições da Psicologia para a Educação (LARROCA, 2007). Assim, os cursos de formação de professores fronteiriços têm o imperativo de contribuir, direta ou indiretamente, com o desenvolvimento de práticas pedagógicas que potencializem a convivência e o respeito à diversidade. Para isso, é necessário que, desde o seu processo de formação inicial, o professor seja sensibilizado e preparado para atuar na e para a diversidade.

Com base nisso, foi possível o desenvolvimento de propostas pedagógicas mais próximas do cotidiano dos estudantes da fronteira. Portanto, pode-se considerar as propostas apresentadas pelos estudantes E1, E2 e E3, do curso de Licenciatura em Matemática, como possíveis práticas que cooperam para garantir os direitos humanos dos estudantes brasiguaios. As sugestões de aulas apresentadas contribuem para "ir além da noção de competência técnica, passando a reconhecer o sujeito/aluno como 
REVISTAELETRONICA

Hinerilings

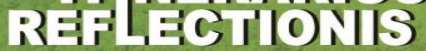

Volume, 14, n.1, Ano 2017.

omnilateral, isto é, simultaneamente cognitivo, afetivo, cultural, biológico, estético, lúdico, sexual, comportamental, social, econômico, político e histórico" (LARROCA, 2007, p. 65).

Nesse processo, a disciplina de Psicologia contribuiu ao trabalhar as matrizes epistemológicas - behaviorismo, cognitivismo, humanismo e interacionismo - sem perder de vista as demandas reais do contexto escolar demonstrados nas pesquisas discutidas, além de despertar o respeito à diversidade, com a valorização do ser humano em seus diferentes aspectos, cooperando "para que a escola seja reinventada e se afirme como um lócus privilegiado de formação de novas identidades e mentalidades capazes de construir respostas, sempre com caráter provisório" [...] (CANDAU, 2012, p. 192).

Contudo, não se pode perder de vista que esse relato de experiência se constitui de discussões e apresentações de sugestões metodológicas. Sugere-se como relevante o desenvolvimento e efetivação das propostas na prática, no cotidiano das escolas, na realidade das salas de aula e a socialização dos resultados. Tal atuação possibilitaria, a partir do aporte teórico da Psicologia da Educação, uma práxis pedagógica no Ensino Básico, a construção de uma ação-reflexão-ação na formação inicial para o magistério.

\section{Referências}

CANDAU, V. M. F.. Diferenças culturais, cotidiano escolar e práticas pedagógicas. Currículo sem Fronteiras, v.11, n.2, pp.240-255, Jul/Dez 2011. Disponível em: < http://www.curriculosemfronteiras.org/vol11iss2articles/candau.pdf > Acesso em: 03 de março de 2016.

Multiculturalismo e educação: desafios para a prática pedagógica. In: MOREIRA, Antônio Flávio; CANDAU, Vera Maria Ferrão (Orgs.). Multiculturalismo Diferenças Culturais e Práticas Pedagógicas. 2.ed. Petrópolis, RJ: Vozes, 2008.

Escola, inclusão social e diferenças culturais. XVI ENDIPE - Encontro Nacional de Didática e Práticas de Ensino - UNICAMP - Campinas, Junqueira \& Marin Editores, Livro 1, 2012. Disponível em:

http://www.infoteca.inf.br/endipe/smarty/templates/arquivos_template/upload_arquivos/ acervo/docs/0019s.pdf Acesso em: 2 de ago. 2016.

CARVALHO, R. E.. Removendo barreiras para a aprendizagem: educação inclusiva. 10 ed. Porto Alegre: Mediação, 2010.

DALINGHAUS, I. V.. Cultura, hibridismo e ensino-aprendizagem em contexto fronteiriço. Cadernos de Pós-Graduação em Letras (Online), v. 13, p. 01-14, 2013. 
REVISTAELETRONICA

H HERAiugs

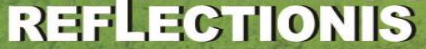

Volume, 14, n.1, Ano 2017.

Disponível em: <http://www.mackenzie.br/26891.html> Acesso em: 10 de abril de 2016.

DECLARAÇÃO DE SALAMANCA. Procedimentos-padrão das Nações Unidas para a Equalização de Oportunidades para Pessoas Portadoras de Deficiências. Resolução das Nações Unidas adotada em assembleia geral, Espanha, 1996.

FEITOSA, R. A.; BODIÃO, I. S.. As teorias sobre o "professor reflexivo" e suas possibilidades para a formação docente na área de Ciências da Natureza. Revista entreideias, v. 4, n. 1, p. 185-199, jan./jun. 2015. Disponível em:

<https://portalseer.ufba.br/index.php/entreideias/article/viewFile/9776/9485> Acesso em: 10 de abril de 2016.

INEP. Resultados Finais do Censo Escolar 2014. Instituto Nacional de Estudos e Pesquisas Educacionais Anísio Teixeira. Disponível em:

$<$ http://portal.inep.gov.br/basica-censo-escolar-matricula>. Acesso em: 1 de abril de 2016.

LAROCCA, P. Ensino de Psicologia e seus fins na formação de professores: uma discussão mais que necessária. Temas em Psicologia, Vol. 15, n. 1, 2007, pp.57 - 68 Disponível em: http://pepsic.bvsalud.org/pdf/tp/v15n1/07.pdf. Acesso em: 20 de Ago. de 2015.

MARCHESI, A. Da linguagem da deficiência às escolas inclusivas. In: COLL, C.; MARCHESI, A.; PALACIOS, J. (Org.). Desenvolvimento psicológico e educação. Vol. 3.2 ed. Tradução de Fátima Murad. Porto Alegre: Artmed, 2010, p.15-30.

MELO, S. M et al.. Relações conflituosas no ensino em região de fronteira.

Interletras, v. 5, n. 23, Março/Setembro, 2016. Disponível em: <http://www.unigran.br/interletras/conteudo/artigos/21.pdf> Acesso em: 20 de jun. de 2016.

NUNES, F. G.. Projetos de formação escolar para escolas em áreas de fronteira. Revista da ANPEGE, v. 7, n. 1, número especial, p. 205-216, out. 2011. Disponível em: <http://anpege.org.br/revista/ojs-2.4.6/index.php/anpege08/article/view/156> Acesso em: 15 de maio de 2016.

PEREIRA, J. H. V.. Diversidade cultural nas escolas de fronteiras internacionais: o caso de Mato Grosso do Sul. Revista Múltiplas Leituras, v.2, n. 1, p. 51-63, jan. / jun. 2009. Disponível em: <https://www.metodista.br/revistas/revistasims/index.php/ML/article/view/327/325>. Acesso em: 2 de março de 2016.

SANTANA, M. L. S. et al.. O brincar como elemento de inclusão de crianças caracterizadas com transtornos do espectro autista. Interfaces da Educação, Paranaíba, v.7, n.19, p.48-65, 2016. Disponível em:

$<$ http://periodicosonline.uems.br/index.php/interfaces/article/view/1061> . Aceso em: 06 ago. 2016. 
Volume, 14, n.1, Ano 2017.

VIGOTSKI, L. S. A defectologia e o estudo do desenvolvimento e da educação da criança anormal. Educ. Pesqui., São Paulo, v. 37, n. 4, p. 863-869, dez. 2011. Disponível em: <http://www.scielo.br/scielo.php?script=sci_arttext\&pid=S151797022011000400012\&lng=en\&nrm=iso>. Acesso em: 06 fev. 2016.

A formação social da mente. São Paulo: Martins Fontes, 2009.

2007. Construção do pensamento e da linguagem. São Paulo: Martins Fontes, 